\title{
Experimental Research on Two-step Cooling Mechanism of the Oxide Film of ELID Grinding Wheel
}

\author{
JiCai KUAI $^{\text {a }}$, JiangWei WANG ${ }^{\mathrm{b}}$ and ChengRan JIANG ${ }^{\mathrm{c}}$ \\ School of Mechanical and Power Engineering, Henan Polytechnic University, Jiaozuo, Henan, \\ 454003, China
}

ahitgjc@163.com

\begin{abstract}
This paper conducts theoretical analysis on the presence of absorbed water and lattice water in the oxide film of ELID grinding wheel, carries out experimental study by applying X-ray (XRD) diffractometer, infrared spectrometer, and thermal gravimetric analyzer TG-DSC, and further proposes the two-step cooling mechanism of the absorbed water and lattice water in the oxide film of ELID grinding wheel. The study shows that there are adsorbed water and lattice water in ELID oxide film, and the cooling effect of adsorbed water and lattice water makes ELID grinding better cool the grinding zone, and get good grinding surface quality more easily.
\end{abstract}

Keywords: ELID (Electrolytic In-process Dressing) grinding, oxide film, adsorbed water, lattice water, two-step cooling.

\section{Introduction}

ELID grinding technology is used in ultra-precision grinding of the materials which are difficult to be processed, and it has important applications in aerospace, national defense, equipment manufacturing, automotive, instrumentation and other fields [1]. High-precision grinding of ELID grinding is closely related to the oxide film generated by the electrolysis on grinding wheel surface [2] This layer of oxide film can absorb vibration, isolate wheel base, reduce grinding depth, and assist in polishing and grinding surface, which makes ELID grinding technology be more suitable for ultra-precision grinding than traditional grinding technology, and can help achieve higher surface quality[3]

Given the importance of the oxide film on grinding wheel surface, many researchers at home and abroad conduct extensive research. Guan Jialiang studied the performance of the fresh oxide film, and uses compressed air to blow off the oxide film on wheel surface, in order to characterize the adsorption capacity of the oxide film[4]; T. Kato et al studied the friction and wear property of the oxide film[5]; based on the previous research, I studied the 
mechanical properties of oxide film and characterize the variation law of oxide film hardness, elastic modulus and stiffness by using nanoindentation technique[6]. Omori studied the polishing performance of oxide film, and assumes that the oxide film can absorb vibration, carry grain, isolate wheel base, avoid scratching the machined surface and so on[7]. Above research results described the performance of the oxide film from different sides respectively, but there is no systematic research on the absorbed water and lattice water in oxide film and their impact on ELID grinding process.

On the basis of previous studies, this paper theoretically analyzes the presence of adsorbed water and lattice water in the oxide film of ELID grinding, and then conducts actual measurement on the adsorbed water and lattice water in oxide film by using X-ray (XRD) diffractometer, Fourier transform infrared spectrometer, TG-DSC thermal gravimetric analyzer and other testing technology, and compares the results with the theoretical calculations.

\section{Experiment on the Cooling Mechanism of the Oxide Film on ELID Grinding Wheel Surface}

\subsection{Experiment Equipment and Method.}

The experiment preparation includes ELID grinding equipment, ELID power supply, ELID electrolyte, iron-based diamond wheel W40, W10, W1.5, Neo X-ray (XRD) diffractometer Ultima IV, copper target, $6^{\circ} /$ min of scanning speed, $20^{\circ}-80^{\circ}$ of scanning angle, TG-DSC thermal gravimetric analyzer (Netzsch STA 449 F3 Jupiter), and Fourier transform infrared spectrometer Magna-IR 750. Methods: first conducting pre-electrolysis on iron-based diamond wheel of W40, W10, W1.5 respectively, then scraping the oxide film on the wheel surface and finally conducting test by applying XRD diffractometer, infrared spectrometer, and TG-DSC analyzer. Use XRD diffractometer to measure the adsorbed water and lattice water in the oxide film at room temperature; use infrared spectrometer to measure the vibration band of the water in the oxide film at room temperature; have $0-600{ }^{\circ} \mathrm{C}$ of heating temperature, $10{ }^{\circ} \mathrm{C} / \mathrm{min}$ of heating rate, and 1 hour of heating as test conditions, to measure TG curve, DTG curve and DSC curve of oxide film, thus obtaining the variation law of adsorbed water evaporation and lattice water dehydration in oxide film with temperature change.

\subsection{Experimental Results and Discussion.}

The results are shown in Figure 1, Figure 2 and Figure 3. It can be seen from Figure 1 that XRD diffraction pattern contains lattice water component: PDF card No. 29-0713 and 08-0098, chemical formula $\mathrm{Fe}+3 \mathrm{O}(\mathrm{OH})$, which can also be written as $\mathrm{Fe}(\mathrm{OH}) 3$ and $\mathrm{Fe} 2 \mathrm{O} 3 \cdot \mathrm{H} 2 \mathrm{O}$. Furthermore, the oxide film generated from the pre-electrolysis of wheel surface is in a wet state, which contains a large amount of electrolyte, so the gap in the oxide film scraped contains much absorbed water. It can be preliminarily judged that oxide film contains adsorbed water and lattice water. 


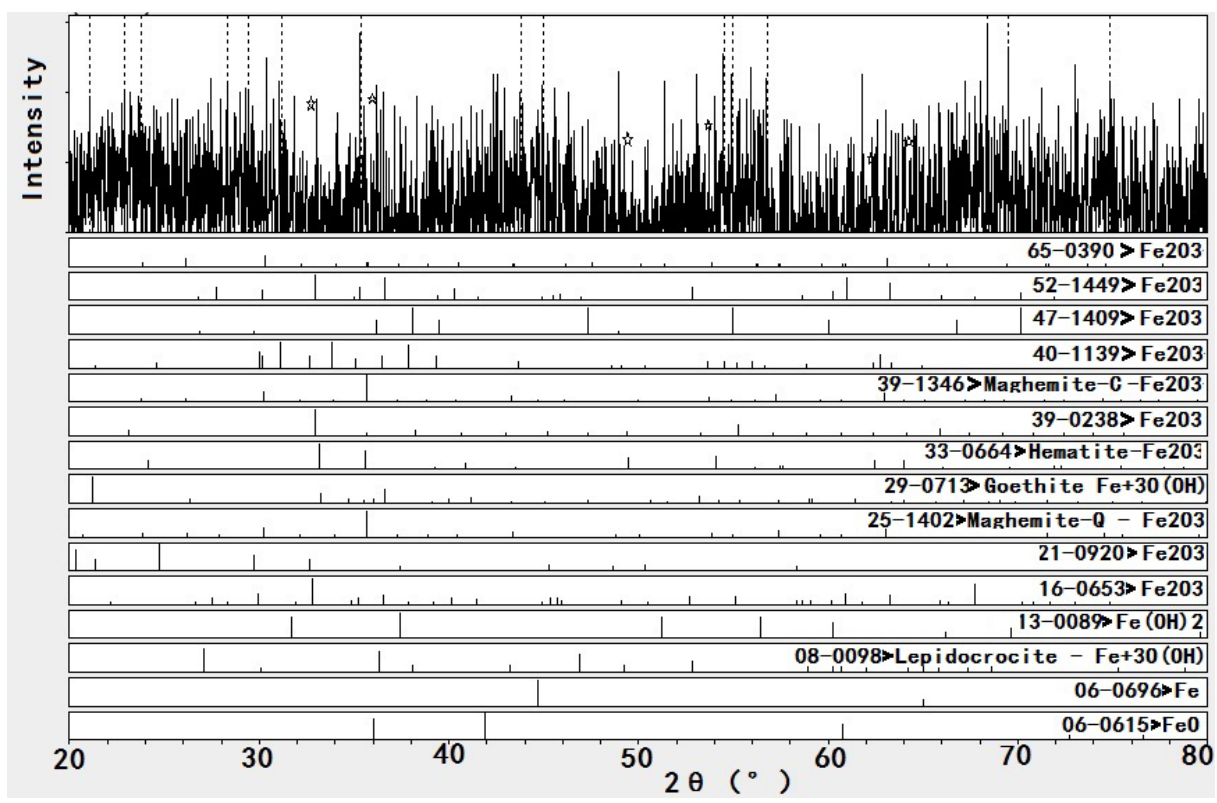

Fig. 1 XRD Test on the Oxide Film of ELID Grinding Wheel of W1.5

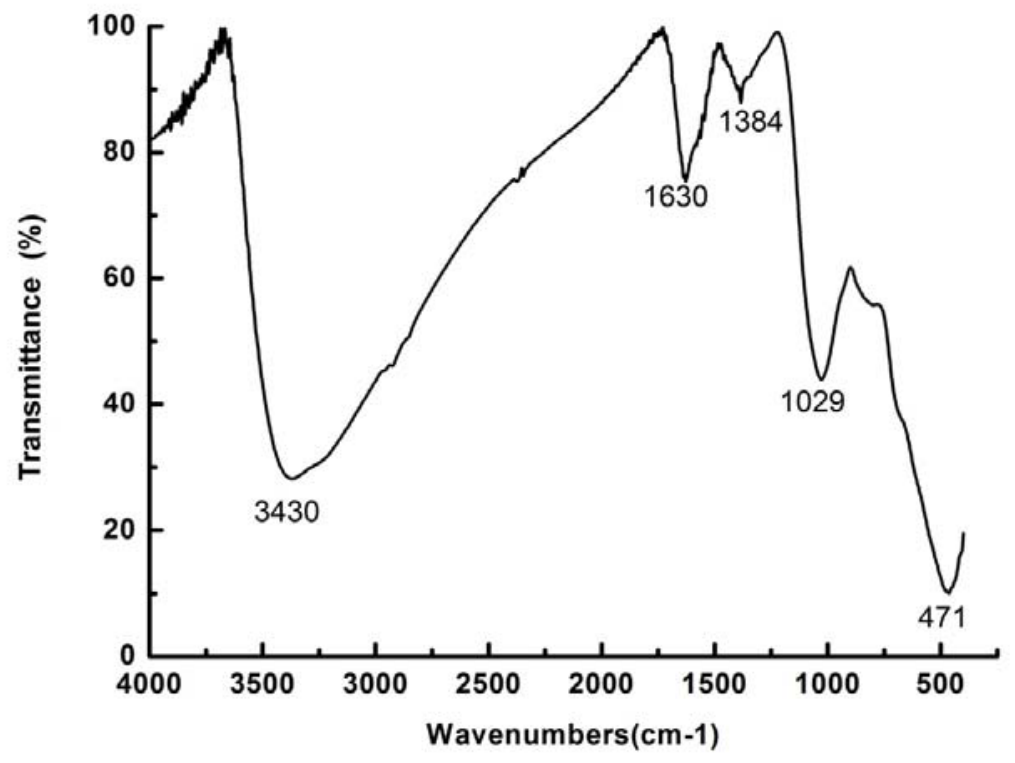

Fig. 2 Infrared Spectroscopy Test on the Oxide Film of ELID Grinding Wheel

Figure 2 is the oxide film infrared spectra of W1.5 wheel. It can be seen from Figure 2 that there are vibration peaks of $471,1029,1384,1630$ and 3430 , which can refer to literature. The standard atlas shows that 471 is the vibration peak of Fe-O, indicating the presence of 
iron oxide in oxide film; 1029 is the $\mathrm{Fe}-\mathrm{O}$ vibration band of $\alpha$-Fe2O3 powder IR spectrum, indicating that the oxide film contains $\alpha-\mathrm{Fe} 2 \mathrm{O} 3 ; 1384$ is the vibration band of $\mathrm{NO} 3$ nitrate, indicating that the oxide film contains the adsorbed component of electrolyte; 1630 is the bending vibration band of water; the range around 3430 is the symmetric and antisymmetric stretching vibration band of absorbed water, indicating that the oxide film contains water. Thus, comparing Figure. 2 and Figure. 1, the oxide film indeed contains the component of lattice water.

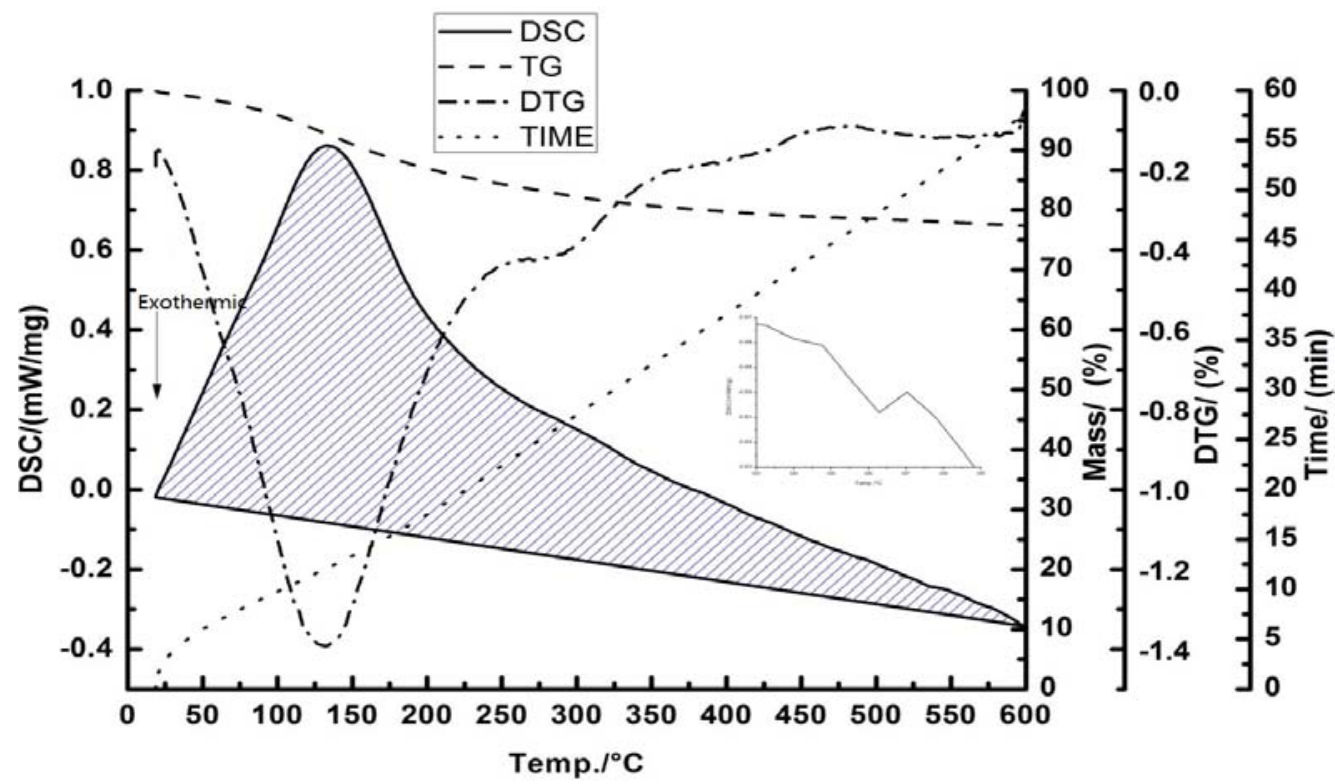

Fig. 3 TG-DSC Test on the Oxide Film of ELID Grinding Wheel of W1.5

Figure 3 is the TG-DSC test result of the oxide film of W1.5 grinding wheel. In Figure 3, TG and DTG curves show greater weight loss occurring at $120{ }^{\circ} \mathrm{C}$, and DSC curve shows the weightlessness accompanied by a large endothermic peak, and endothermic reaction occurs. The weight loss at this time is mainly caused by the evaporation of adsorbed water in the pores of oxide film, accompanying by endothermic phenomenon. It can be seen from the TG curve in Figure 3 that smaller weight loss occurs at $250{ }^{\circ} \mathrm{C}-300{ }^{\circ} \mathrm{C}$, quality changes from $84.35 \%$ to $82.22 \%$, mass loss is $2.13 \%$, and DTG curve has obvious steps, accompanying by certain endothermic reaction. After calculation, the mass loss is equal to the lattice water quality in iron oxide, which can determine that the weight loss occurring at $250{ }^{\circ} \mathrm{C}-300{ }^{\circ} \mathrm{C}$ is due to the lattice water dehydration in oxide film, and dehydration of hydrated iron oxide in the oxide film of grinding wheel generates $\gamma$-Fe2O3. At about $500{ }^{\circ} \mathrm{C}, \mathrm{TG}, \mathrm{DTG}$ curves tend to be stable, and no weight loss occurs. After careful analysis of Figure 3, as is shown in the partial view of Figure 3, a small exothermic peak occurs at $543{ }^{\circ} \mathrm{C}-549{ }^{\circ} \mathrm{C}$, and TG curve, DTG curve have no significant change, indicating that mass loss caused by the adsorbed water and lattice water in the oxide film has basically completed at this time. It can be determined that exothermic phenomenon appearing at $543{ }^{\circ} \mathrm{C}-549{ }^{\circ} \mathrm{C}$ is due to the heat released in the transformation from $\gamma$-Fe2 $\mathrm{O} 3$ to $\alpha-\mathrm{Fe} 2 \mathrm{O} 3$ in oxide film. 


\section{Impact of the Adsorbed Water and Lattice Water in Oxide Film on ELID Grinding Quality}

\subsection{Impact on ELID Grinding Temperature.}

Under the high temperature of grinding zone, the absorbed water and lattice water in oxide film are heated, and absorbed water evaporation and lattice water dehydration are completed in turn. The above discussion shows that adsorbed water evaporation needs to absorb heat and lattice water dehydration also needs to absorb heat, which will reduce the temperature of ELID grinding zone to some extent.

\subsection{Impact on ELID Grinding Surface Quality.}

For the materials difficult to be processed, surface residual stress is an important indicator to measure the quality of grinding surface. Because the grinding heat of traditional grinding method is difficult to distribute, grinding area is difficult to be reliably cooled. Therefore, the grinding heat gathers in the grinding zone, making residual stress of grinding surface manifest as greater tensile stress, thus easily causing stress concentration and often resulting in cracks and other defects. For ELID grinding, due to the presence of absorbed water and lattice water in oxide film, compared with traditional grinding, it can better cool grinding zone, which is advantageous to reducing the residual stress of ELID grinding surface, avoiding or reducing stress concentration and improving the surface quality of ELID grinding.

\subsection{Impact on Oxide Film Composition.}

Large amount of grinding heat gathering in the grinding zone generates very high grinding temperature. Under the influence of high grinding temperature, oxide film composition not only has physical change like absorbed water evaporation and lattice water dehydration, but also has chemical conversion, which is shown in Formula (1).

$$
\gamma-\mathrm{Fe}_{2} \mathrm{O}_{3} \stackrel{\Delta}{\rightarrow} \alpha-\mathrm{Fe}_{2} \mathrm{O}_{3}
$$

Therefore, theoretically, the conversion from $\gamma$-Fe2O3 to $\alpha$-Fe2O3 in oxide film is preliminarily determined [8]. In Figure 1, the XRD testing atlas indeed contains $\alpha-\mathrm{Fe} 2 \mathrm{O} 3$, namely PDF standard card: 33-0664. It can be known from the test results of IR spectrum in Figure 2 that $1029 \mathrm{~cm}^{-1}$ is the $\mathrm{Fe}-\mathrm{O}$ vibration band of $\alpha-\mathrm{Fe} 2 \mathrm{O} 3$ powder IR spectrum, indicating that the oxide film contains $\alpha-\mathrm{Fe} 2 \mathrm{O} 3$. Both confirm each other, proving that the oxide film of ELID grinding wheel does contain $\alpha$-Fe2O3. And as we all know, $\alpha-\mathrm{Fe} 2 \mathrm{O} 3$ is an excellent polishing agent, its polishing performance is just inferior to cerium oxide, and it is commonly used in ultra-precision polishing of quartz glass, silicon and other materials that have high requirements for polishing performance. Therefore, oxide film of ELID grinding wheel is qualified with auxiliary polishing performance, namely accompanying fine polishing effect of $\alpha-\mathrm{Fe} 2 \mathrm{O} 3$ in the oxide film in micro-cutting of the abrasive particles of grinding wheel, which is the root cause for grinding technology of ELID grinding wheel being able to achieve excellent grinding surface quality. 


\section{Summary}

This paper studies the cooling mechanism of adsorbed water and lattice water in the oxide film of ELID grinding wheel, and discusses the impact on grinding zone temperature and the impact of the composition conversion of oxide film on ELID grinding surface quality. Some useful results are listed as follows.

1) XRD and infrared analysis show that adsorbed water and lattice water do exist in the oxide film of ELID grinding wheel. And thermal gravimetric analysis shows that the adsorbed water and lattice water can cool the grinding zone, and reduce the grinding temperature to a certain extent.

2)Because ELID grinding temperature is lower than conventional grinding temperature, residual stress of ELID grinding surface is smaller, which is advantageous for getting excellent grinding surface quality.

3) XRD and infrared analysis show that the oxide film of ELID grinding wheel contains $\alpha$-Fe2O3, so ELID oxide film is qualified with auxiliary polishing performance, which is the root cause for ELID grinding technology being able to achieve excellent grinding surface quality.

\section{Acknowledgement}

The authors wish to thank the helpful comments and suggestions from my teachers of Harbin Institute of Technology. This project is supported by the National Natural Science Foundation of China (Grant No.51475147) and the key project of science and technology of Educational Commission of Henan Province of China(Grant No.13A460341).

\section{References}

1. S.H. Yin, X.L. Zeng, Y.F. Fan, Research progresses of ELID mirror grinding technology, China Mechanical Engineering. 21 (2010) 750-755.

2. J.C. Kuai, Friction coefficient of nano-ceramic polished by oxide film on ELID grinding wheel, Advanced Materials Research. 669 (2013) 91-94.

3. H. Ohmori, K. Katahira, Y. Akinou, Investigation on grinding characteristics and surface-modifying effects of biocompatible Co-Cr alloy, CIRP Annals - Manufacturing Technology. 55 (2006) 597- 600.

4. J.L. Guan, D.M. Guo, Z.J. Yuan, Research on the characteristics and roles of oxide film on grinding wheel of ELID mirror surface grinding, Chinese Journal of Mechanical Engineering. 36 (2000) 89-92.

5. T. Kato, N. Itoh, H. Ohmori, Estimation of tribological characteristics of electrolyzed oxide layers on ELID-grinding wheel surfaces, Key Engineering Materials. 257-258 (2004) 257-262.

6. J.C. Kuai, F.H. Zhang, Y. Zhang, Mechanical properties of oxide film on elid grinding wheel surface, Nanotechnology and Precision Engineering. 8 (2010) 447-451.

7. H. Ohmori, T. Nakagawa, Utilization of nonlinear conditions in precision grinding with ELID (Electrolytic in-process dressing) for fabrication of hard material components, CIRP Annals - Manufacturing Technology. 46 (1997) 261-264.

8. J.C. Kuai, Discovery of $\alpha-\mathrm{Fe} 2 \mathrm{O} 3$ in the oxide film on ELID grinding wheel, Advanced Materials Research. 1061-1062 (2015) 446-449. 